\title{
Double brooding and offspring desertion in the barn owl Tyto alba
}

\author{
Paul Béziers and Alexandre Roulin \\ P. Béziers (paul.beziers@unil.ch) and A. Roulin, Dept of Ecology and Evolution, Univ. of Lausanne, Biophore Building, CH-1015 Lausanne, \\ Switzerland.
}

\begin{abstract}
Many bird species produce two annual broods during a single breeding season. However, not all individuals reproduce twice in the same year suggesting that double brooding is condition-dependent. In contrast to most raptors and owls, the barn owl Tyto alba produces two annual clutches in most worldwide distributed populations. Nevertheless, the determinants of double brooding are still poorly studied. We performed such a study in a Swiss barn owl population monitored between 1990 and 2014. The annual frequency of double brooding varied from 0 to $14 \%$ for males and 0 to $59 \%$ for females. The likelihood of double brooding was higher when individuals initiated their first clutch early rather than late in the season and when males had few rather than many offspring at the first nest. Despite the reproductive benefits of double brooding (single- and double-brooded individuals produced 3.97 \pm 0.11 and $7.07 \pm 0.24$ fledglings, respectively), double brooding appears to be traded off against offspring quality because at the first nest double-brooded males produced poorer quality offspring than single-brooded males. This might explain why females desert their first mate to produce a second brood with another male without jeopardizing reproductive success at the first nest. Furthermore, the reproductive cycle being very long in the barn owl (120 d from start of laying to offspring independence), selection may have favoured behaviours that accelerate the initiation of a second annual brood. Accordingly, half of the double-brooded females abandoned their young offspring to look for a new partner in order to initiate the second breeding attempt, $9.48 \mathrm{~d}$ earlier than when producing the second brood with the same partner. We conclude that male and female barn owls adopt different reproductive strategies. Females have more opportunities to reproduce twice in a single season than males because mothers are not strictly required during the entire rearing period in contrast to fathers. A high proportion of male floaters may also encourage females to desert their first brood to re-nest with a new male who is free of parental care duties.
\end{abstract}

Breeding multiple times in the same breeding season is relatively frequent in birds (Geupel and Desante 1990, Alker and Redfern 1996, Fargallo et al. 1996, Jamieson 2011, Jacobs et al. 2013, Tarwater and Beissinger 2013, Carro et al. 2014, Hoffmann et al. 2015). Although breeding twice allows individuals to produce more offspring than single-brooded conspecifics (Geupel and Desante 1990, Nagy and Holmes 2005a, b, Husby et al. 2009, Carro et al. 2014, Hoffmann et al. 2015), not all of them opt to do so because the costs associated with double brooding are substantial. For instance, breeding twice during a single season may depend on experience (age), body condition and past investment in various activities such as body maintenance and reproduction (Geupel and Desante 1990, Verhulst and Hut 1996, Jacobs et al. 2013, Hoffmann et al. 2015). The decision to produce a second annual brood may also depend on the mate's ability to pursue reproductive activities over a longer period of time, and if he or she is not able to reproduce again, this decision will depend on the availability of non-breeders or conspecifics that failed a previous reproductive attempt and are willing to produce a replacement brood. Accordingly, in the Kentish plover Charadrius alexandrines, females initiate more often a second clutch than males because the operational sex ratio is biased towards males, offering to females more opportunities to re-mate (Szekely et al. 1999). Because in species such as raptors and owls, the male is essential to feed the progeny, females have more occasions to abandon their brood in the middle of the rearing period to start a second breeding attempt with a new mate as shown in the Tengmalm's owl Aegolius funereus (Eldegard and Sonerud 2009, Korpimaki et al. 2011). In other species like the treecreeper Certhia familiaris, breeding partners raise their first and second annual clutches together (Kuitunen et al. 1996). There is thus ample intra- and interspecific sex-specific variation in the likelihood of breeding twice in the same season.

Producing a second brood also depends on life history traits such as the duration of the breeding season, nestling development time and timing of the first clutch. Several studies have indeed shown that individuals breeding early in the season have a higher probability of producing a second annual clutch than late breeders (Geupel and Desante 1990, Verhulst and Hut 1996, Eldegard and Sonerud 2009, Jacobs et al. 2013, Carro et al. 2014, Hoffmann et al. 2015). The quality of the breeding territory and the abundance of resources have also a profound impact on the likelihood of breeding twice in the same season (Beissinger 1986, Marks and Perkins 1999, Moore and Morris 2005, Nagy 
and Holmes 2005b, Eldegard and Sonerud 2009, 2012, Carro et al. 2014). For instance, female black-throated blue warblers Dendroica caerulescens experimentally fed with extra food were more likely to initiate a second brood than unfed females (Nagy and Holmes 2005a). Reproducing twice in the same season may also affect the quality and survival of the offspring at the first nest, as parents will have less time to invest in parental care (Geupel and Desante 1990, Eldegard and Sonerud 2009). Accordingly, parental care at the first annual breeding attempt was shown to be of lower quality in double-brooded than single-brooded parents (Geupel and Desante 1990, Verhulst et al. 1997, Eldegard and Sonerud 2009). This review about the various determinants of producing a second annual brood emphasizes the possibility that reproducing twice in the same year is traded off against selfmaintenance and reproductive success at the first brood.

Most species of raptors and owls produce a single annual brood, especially in large species which have long breeding cycles with extended post-fledging parental care (Newton 1979). Double brooding is usually a rare event as observed in the American Falco sparverius and European kestrels Falco tinnuculus (Stahlecker and Griese 1977, Toland 1985, van Heerden et al. 1994, Fargallo et al. 1996, Steenhof and Peterson 1997), the Tengmalm's owl Aegolius funereus (Eldegard and Sonerud 2009, Korpimaki et al. 2011, Eldegard and Sonerud 2012), the burrowing owl Athene cunicularia (Millsap 1990) and the long-eared owl Asio otus (Marks and Perkins 1999). In these species, producing two annual clutches occurs only in years with exceptional breeding conditions. Frequent double brooding has been reported in only a few raptors, including the pale chanting goshawk Melierax canorus, (annual frequency of double brooding ranges from 0 to 30\%) (Malan et al. 1997), the crested caracaras Caracara cheriway (11-19\%) (Morrison 1998), and the black sparrowhawk Accipiter melanoleucus (Curtis et al. 2005). The barn owl Tyto alba is particularly interesting in this respect because it has a high reproductive potential with individuals being able to produce up to three broods in a single year, each clutch comprising sometimes more than 10 eggs (Stopper 1983, Lenton 1984a, b, Baudvin 1986, Lander et al. 1991, Muller 1991, Andrusiak 1994, Marti 1997, Martinez and Lopez 1999, Debrot et al. 2001, Shawyer 2003, Kniprath and Stier 2008). Furthermore, the barn owl has one of the longest breeding cycle (Curtis et al. 2005) with incubation lasting ca $32 \mathrm{~d}$, nestlings staying ca $60 \mathrm{~d}$ in their nest and post-fledging parental care extending to $30 \mathrm{~d}$ (Bunn et al. 1982, Courtney and Debus 2006). Even in the largest Tyto species such as the masked owl Tyto novaehollandiae and sooty owl Tyto tenebricosa in which postfledging parental care can last 3 months, double brooding can occur if food conditions are exceptional (Debus 1994, 1997). Although a number of studies have reported double brooding in different barn owl populations across the world, few of them have evaluated the factors contributing to its occurrence (Baudvin 1986, Marti 1994, Kniprath and Stier 2008). In these studies, second annual clutches were shown to be more frequent in years with abundant food resources and when most breeding pairs laid their first clutch early in the season.

In the present study, our aim is to examine the frequency of double brooding in a Swiss population of barn owls Tyto alba between 1990 and 2014, and identify the causes and consequences of double brooding. More specifically, we investigated whether the probability of producing a second annual brood is associated with the timing of laying and reproductive success at the first brood, and with age of the breeders. We examined which factor (age, laying date and reproductive success at the first nest) predicts whether breeders use different sites to produce the first and second annual clutch. Finally, we studied which of these factors predict whether a female changes mate between the first and second annual brood.

\section{Methods}

The data were collected during 25 breeding seasons between 1990 and 2014 in a population of barn owls located in western Switzerland $\left(46^{\circ} 49^{\prime} \mathrm{N}, 06^{\circ} 56^{\prime} \mathrm{E}\right)$ in a study area of $1070 \mathrm{~km}^{2}$ at an altitude of $420-730 \mathrm{~m}$. In 1990 and 1991 , 110 nest-boxes were fixed to the external wall of barns to progressively reach 134 boxes in 2005; from 2006 to 2014 we fixed new boxes to reach 350 units. Nest-boxes were regularly visited between March and October to record breeding parameters (laying date, clutch size, number of hatchlings and brood size at fledging). We also measured body mass (to the nearest $\mathrm{g}$ ) and wing length (to the nearest $\mathrm{mm}$ ) of nestlings at each of our visits. Nestling age was determined soon after hatching (0-25 d) (Roulin 2004), and hence wing length measured at a later stage was sensitive not only to age but body condition. A blood sample was taken to identify nestling sex (Roulin et al. 1999).

Between 1990 and 2014, we recorded 1177 first annual clutches and captured 1169 breeding females and 1030 breeding males. Out of 145 recorded second annual clutches, we captured 144 breeding females and 78 of the breeding males; for 127 double brooding females we could identify the identity of their male at the first and second annual broods. From the 18 cases where we captured the breeding male at only the first or second clutch, we could deduce that the same male produced the two successive annual clutches in three cases because the female stayed in the same nestbox to produce her second annual clutch and because the second clutch was laid long before the first offspring were independent from their father. In 5 cases, we deduced that it was a different male because the distance between breeding sites of the first and second annual clutches were too far (more than $3.5 \mathrm{~km}$ ) for the father to assume the two nests simultaneously. All females were captured while they were incubating the eggs and males were either captured at the same time as the females or later when feeding their offspring. Of the 1997 breeding adults, 969 had been ringed as nestlings and hence their age was known with precision; the age of 1028 other individuals ringed as adult was estimated from the moult pattern (Taylor 1993). We classified birds in the age class 'yearling' (i.e. individuals in their first-year of life) and if older as 'adult'. An individual was considered as 'double-brooder' if it successfully produced a first brood (i.e. at least one nestling fledged) and a second clutch in the same or different site. The term 'site' refers to the barn where a pair produced a clutch. Some barns have two nest-boxes, which enables females to produce a second annual clutch in the same site. The 236 individuals that failed to produce 
any fledglings and laid a replacement clutch were not considered in the present study. Forty-one polygamous males who were rearing two broods simultaneously were considered as polygamous but not as double-brooders, and hence they are not considered here.

\section{Statistical procedure}

The analyses were performed with R Studio (ver. 0.98.501) (R Core Team 2004) and the libraries lme4 (mixed models), sim and arm (to compute confidence intervals) and pbkrtest (model selection). We ran generalized linear mixed models (GLMMs, function glmer) when the data followed binomial and Poisson distributions, and linear mixed models (LMERs, function lmer) for normally distributed variables. Because a number of individuals bred in more than one year, we implemented individual identity and year as random variables to avoid pseudo-replication. We analysed nestling body mass and fledging success in order to investigate the potential fitness effects of double brooding. We ran linear mixed models (function lmer, package lme4) to test whether offspring body mass differed between single- and double-brooded parents. We first examined whether nestling body mass (measured between 0 and $32 \mathrm{~d}$ of age) predicted whether parents produced a second brood later on; $32 \mathrm{~d}$ is before mothers start to desert their brood to produce a second brood with another partner (Roulin 2002). This analysis is therefore useful to examine whether parents are more likely to produce a second brood if rearing conditions are good (i.e. if their offspring are heavy rather than light). In a second model, we specifically investigated whether producing a second annual clutch negatively affected nestling body mass at the first annual nest. For this model, we considered body mass measured between 45 and $60 \mathrm{~d}$ of age, which corresponds to the period when the mother can already abandon the nest to produce a second clutch. These models were performed for male and female parents separately because the probability of producing a second brood differs between males and females. For all analyses, the initial full models included nestling age in days, age ${ }^{2}$, age ${ }^{3}$, wing length $(\mathrm{mm})$, time of the day (hour), laying date, brood size, rank of nestling in the within-brood age hierarchy and the number of annual clutches (i.e. 1st or 2nd brood). To account for repeated-measurements of nestling body mass as well as for repeated reproductive events of the parents within or across years, we included nestling and parent identities as random factors. Brood identity and year were also included as random factors.

To evaluate whether the total annual breeding success (i.e. number of fledglings at the first and second nests) is related to the number of clutches produced in a year, we ran a GLMER with a binomial error structure and logit link function (function glmer, package lme4); we introduced the total number of fledglings who survived and died as a dichotomous variable.

All models were simplified using a backward selection procedure where each model is compared against a simpler nested model. We simulated 200 times a set of response values from the null model and calculated the likelihood ratio between the alternative and null model for each response values (function PBmodcomp, package pbkrtest). From these likelihood ratios we estimated a p-value for each response value with the bootstrap method (Faraway 2006) and used them to reduce the model until it contained only significant variables ( $p \leq 0.05$, two tails). Likewise, when the random variables did not explain any significant part of the variation, we removed them from the model to improve its convergence. Assumptions of all statistical tests were verified. The estimates reported in the results section are extracted from the models. For logistic reasons, the number of individuals can vary between analyses for instance because we did not record all reproductive parameters in all individuals. Means are quoted \pm SE.

Data available from the Dryad Digital Repository: $<$ http://dx.doi.org/10.5061/dryad.9sk18> (Béziers and Roulin 2015).

\section{Results}

\section{Frequency of second annual broods}

Between 1990 and 2014, we monitored 1006 males (487 different individuals) producing a first annual brood of which 888 (440 different individuals) raised at least one fledgling (88\%). Of these 888 males, 78 (66 different individuals) produced a second annual brood (8\%). Concerning females, we monitored 1131 first annual broods (664 different individuals) of which 950 (572 different individuals) produced at least one fledgling (84\%). Of these 950 females, 145 (115 different individuals) produced a second annual brood (13\%), a proportion that was significantly higher than in males (chi-squared test: $\chi^{2}{ }_{1}=14.20$, $\mathrm{p}<0.0002)$. Up to $59 \%$ of females and $38 \%$ of males produced two broods in the same year (Table 1) with some individuals double brooding more than once during the 25 year-long study period: 92 females and 54 males double brooded only once, 20 females and 12 males twice and 3 females three times. The number of first clutches produced in a year was not associated with the proportion of second annual clutches (GLM: $Z=-0.20, p=0.84$ ); the model was corrected for the year (fixed factor) as the number of nestboxes increased during the study period.

\section{Factors associated with the probability of producing a second annual clutch}

Males were more likely to produce a second annual clutch if their first brood had been laid early than late in the season (laying date at first annual breeding attempt of single- and double-brooded males is 24 April $\pm 4.1 \mathrm{~d}$ and 24 March \pm $5.8 \mathrm{~d}$, respectively; GLMER: $\mathrm{LR}_{1}=53.23, \mathrm{p}_{\text {boot }}=0.005$ ) and if the number of fledglings at this first breeding attempt was low $\left(\mathrm{LR}_{1}=12.71, \mathrm{p}_{\text {boot }}=0.005\right.$, number of fledglings at first annual breeding attempt of single- and double-brooded males is $4.15 \pm 0.07$ and $3.75 \pm 0.23$, respectively); age class (adult vs yearling) did not predict whether a male produced a second annual clutch $\left(\mathrm{LR}_{1}=1.27, \mathrm{p}_{\mathrm{boot}}=0.25\right)$. In a similar model, where we replaced the number of fledglings by clutch size at the first breeding attempt, clutch size did not predict whether males produced a second annual brood $\left(\mathrm{LR}_{1}=2.28, \mathrm{p}_{\text {boot }}=0.13\right)$. Males who initiated a second annual clutch in a different breeding site than the one of 
Table 1. Frequency of first and second annual clutches in a Swiss barn owl population.

\begin{tabular}{|c|c|c|c|c|c|c|}
\hline \multirow[b]{2}{*}{ Year } & \multicolumn{2}{|c|}{$\begin{array}{c}\text { Number of } 1 \mathrm{st} \\
\text { annual clutches } \\
\end{array}$} & \multicolumn{2}{|c|}{$\begin{array}{l}\text { Number of } 2 \text { nd annual } \\
\text { clutches }\end{array}$} & \multicolumn{2}{|c|}{$\begin{array}{c}\text { Number of individuals } \\
\text { producing a } 2 \text { nd annual } \\
\text { clutch with another } \\
\text { partner than at the } 1 \mathrm{st} \\
\text { annual clutch }\end{array}$} \\
\hline & Females & Males & Females & Males & Females & Males \\
\hline 1990 & 39 & 8 & $2(5 \%)$ & $?$ & $?$ & $?$ \\
\hline 1991 & 26 & 8 & $1(4 \%)$ & $?$ & $?$ & $?$ \\
\hline 1992 & 25 & 23 & 0 & 0 & - & - \\
\hline 1993 & 43 & 42 & $12(28 \%)$ & $9(21 \%)$ & $4(33 \%)$ & $1(11 \%)$ \\
\hline 1994 & 57 & 54 & $3(5 \%)$ & $4(7 \%)$ & 0 & $1(25 \%)$ \\
\hline 1995 & 58 & 58 & $7(12 \%)$ & $3(5 \%)$ & $4(57 \%)$ & 1 (33\%) \\
\hline 1996 & 67 & 61 & $9(13 \%)$ & $4(7 \%)$ & $6(67 \%)$ & 0 \\
\hline 1997 & 34 & 34 & $2(6 \%)$ & $1(3 \%)$ & $1(50 \%)$ & 0 \\
\hline 1998 & 44 & 40 & $6(14 \%)$ & $4(10 \%)$ & $3(50 \%)$ & $1(25 \%)$ \\
\hline 1999 & 41 & 35 & 0 & 0 & 0 & 0 \\
\hline 2000 & 54 & 45 & $1(2 \%)$ & $1(2 \%)$ & $1(100 \%)$ & $1(100 \%)$ \\
\hline 2001 & 52 & 45 & $1(2 \%)$ & 0 & $1(100 \%)$ & 0 \\
\hline 2002 & 77 & 65 & $1(1 \%)$ & 0 & 0 & 0 \\
\hline 2003 & 50 & 45 & 0 & 0 & 0 & 0 \\
\hline 2004 & 30 & 40 & $13(43 \%)$ & $3(8 \%)$ & $10(77 \%)$ & $?$ \\
\hline 2005 & 47 & 51 & $9(19 \%)$ & $2(4 \%)$ & $7(77 \%)$ & $1(50 \%)$ \\
\hline 2006 & 30 & 23 & 0 & 0 & 0 & 0 \\
\hline 2007 & 59 & 60 & $21(36 \%)$ & $10(17 \%)$ & $14(67 \%)$ & $4(40 \%)$ \\
\hline 2008 & 76 & 73 & 0 & 0 & 0 & 0 \\
\hline 2009 & 19 & 18 & $2(11 \%)$ & $1(6 \%)$ & $1(50 \%)$ & $?$ \\
\hline 2010 & 35 & 36 & $10(29 \%)$ & $6(17 \%)$ & $3(30 \%)$ & $1(17 \%)$ \\
\hline 2011 & 40 & 34 & $14(35 \%)$ & $13(38 \%)$ & $4(29 \%)$ & $3(23 \%)$ \\
\hline 2012 & 95 & 74 & $18(19 \%)$ & $14(19 \%)$ & 7 (39\%) & $4(29 \%)$ \\
\hline 2013 & 11 & 9 & 0 & 0 & 0 & 0 \\
\hline 2014 & 22 & 25 & $13(59 \%)$ & $3(8 \%)$ & $8(62 \%)$ & $1(50 \%)$ \\
\hline Total & 1131 & 1006 & $145(13 \%)$ & $78(8 \%)$ & $70(48 \%)$ & $18(23 \%)$ \\
\hline
\end{tabular}

the first brood initiated their second annual clutch earlier $(85.0 \pm 2.3 \mathrm{~d}$ between laying date of first and second annual clutch; range: 44 to $117 \mathrm{~d}$; LMER: $\mathrm{LR}_{1}=7.1, \mathrm{p}_{\text {boot }}=0.01$ ) than males who stayed in the same breeding site (99.5 \pm 4.2 d; range: 54 to $139 \mathrm{~d}$ ). The time interval between laying the two successive annual clutches was not related to laying date at the first breeding attempt $\left(\mathrm{LR}_{1}=3.08, \mathrm{p}_{\text {boot }}=0.10\right)$, male age $\left(\mathrm{LR}_{1}=0.45, \mathrm{P}_{\text {boot }}=0.49\right)$, the distance between the sites where the two clutches were deposited $\left(\mathrm{LR}_{1}=1.25\right.$, $\left.\mathrm{p}_{\text {boot }}=0.30\right)$ and whether males changed partner between first and second annual clutch $\left(\mathrm{LR}_{1}=2.53, \mathrm{p}_{\text {boot }}=0.12\right)$.

We performed a similar model for females because $50 \%$ of them changed mate to produce a second annual breeding attempt, implying that potentially different factors could predict double brooding in males and females. The probability that females produced a second annual clutch increased if the first clutch had been produced early than late in the season (Fig. 1; laying date at first annual breeding attempt of single- and double-brooded females is 22 April $\pm 4.5 \mathrm{~d}$ and 28 March $\pm 3.1 \mathrm{~d}$, respectively; $\mathrm{LR}_{1}=69.01, \mathrm{p}_{\text {boot }}=0.005$ ); number of fledglings, clutch size and age class of females were not significant $\left(\mathrm{p}_{\text {boot }}>0.10\right)$.

Body mass measured between 0 and $32 \mathrm{~d}$ of age in nestlings at the first breeding attempt was not related to whether their mother or father later produced a second annual clutch (GLMER, male: $\mathrm{n}=9041$ measurements of body mass in 4285 nestlings, $\mathrm{LR}_{1}=0.87, \mathrm{p}_{\text {boot }}=0.30$; female: $\mathrm{n}=9289$ measurements of body mass in 4650 nestlings, $\mathrm{LR}_{1}=0.91$, $\left.\mathrm{p}_{\text {boot }}=0.33\right)$.

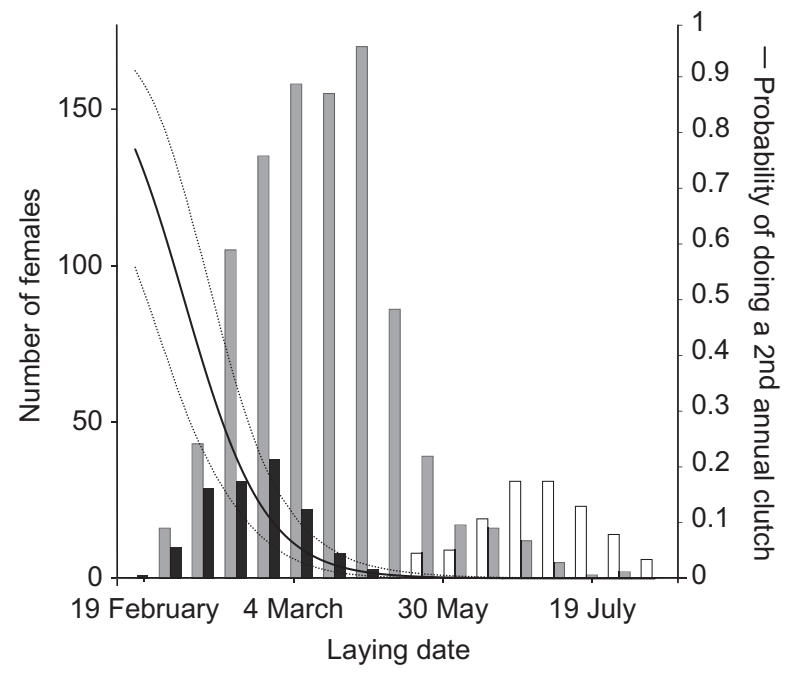

$\square$ Females producing a single clutch

- Double-brooded females producing their 1 st annual clutch $\square$ Double-brooded females producing their $2^{\text {nd }}$ annual clutch

Figure 1. Distribution of laying dates of female barn owls producing a single clutch and of laying dates of the first and second clutch of double-brooded females. The line represents the likelihood of double brooding in relation to laying date of first clutches. The dashed lines represent the $95 \%$ confidence intervals.

\section{Probability of changing site to produce a second annual clutch}

Of the males, 38\% (30 out of 78, Fig. 2) produced their second annual clutch in the same site as the one where they produced their first annual clutch while only $20 \%$ of females (29 out of 145) (chi-square test: $\chi^{2}{ }_{1}=4.97, p=0.026$ ). When considering only the individuals who produced two annual broods in the same site, $27 \%$ of the males $(8$ of 30) changed mate but none of the 29 females $\left(\chi^{2}{ }_{1}=6.93\right.$, $\mathrm{p}=0.008)$. Among the individuals who changed site to produce their second annual brood, $60 \%$ of the females ( 70 out of 116 ) changed mate but only $21 \%$ of the males ( 10 out of 48) $\left(\chi^{2}{ }_{1}=8.34, \mathrm{p}=0.0038\right)$.

The probability that a female changed breeding site between the first and second annual clutches $(29$ females stayed in the same breeding site and 116 changed breeding site) was neither related to her age (GLMER: $\mathrm{LR}_{1}=3.33$, $\left.\mathrm{p}_{\text {boot }}=0.11\right)$, laying date $\left(\mathrm{LR}_{1}=0.30, \mathrm{p}_{\text {boot }}=0.60\right)$ and the number of fledglings at the first annual breeding attempt $\left(\mathrm{LR}_{1}=0.62, \mathrm{p}_{\text {boot }}=0.53\right)$. Although females who changed site laid their second clutch significantly earlier than females who stayed in the same breeding site (24 June $\pm 2.4 \mathrm{~d}$ vs 8 July \pm 3.8 d; GLMER: $\mathrm{LR}_{1}=11.96, \mathrm{p}=0.002$ ), these two groups of females produced a clutch and brood of similar sizes at the first and second breeding attempts $\left(\mathrm{LR}_{1}=0.11\right.$, $\mathrm{p}_{\text {boot }}=0.88$ and $\mathrm{LR}_{1}=0.64, \mathrm{p}_{\text {boot }}=0.42$, respectively).

Females who changed partner and breeding site to produce their second annual brood travelled longer distances than females who changed breeding site but stayed faithful to their first partner ( $4.6 \pm 0.5 \mathrm{~km}$ (range: 0.9 to $29.1 \mathrm{~km}$ ) vs $1.2 \pm 0.1 \mathrm{~km}$ (range: 0.2 to $3.0 \mathrm{~km}$ ); LMER with log transformed distance between the two sites: interaction 'sex by faithfulness' $\left.\mathrm{LR}_{1}=13.35, \mathrm{p}_{\mathrm{boot}}=0.005\right)$. Unlike females, 


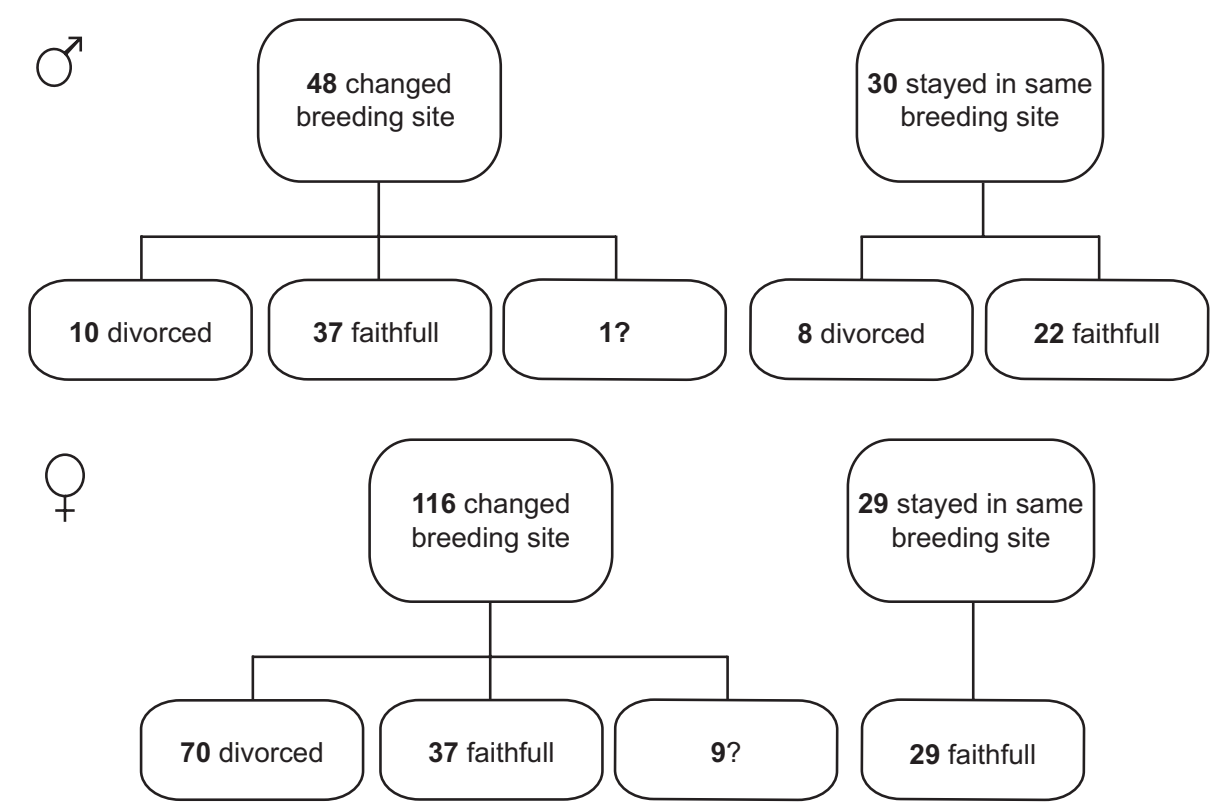

Figure 2. Flow-chart representing the number of females and males who stayed or changed breeding site and those who were faithful or who divorced between first and second annual clutch.

the 10 males who changed partner and breeding site did not move longer distances than the 37 males who changed site but remained faithful to their female partner $(1.5 \pm 0.3 \mathrm{~km}$ (range: 0.1 to $3.3 \mathrm{~km})$ vs $1.1 \pm 0.2 \mathrm{~km}(0.2$ to $2.7 \mathrm{~km})$.

\section{Partner at the second breeding attempt}

Among 136 double-brooded females for which we knew the identity of their mate at the first and second breeding attempts, 66 produced their two annual broods with the same partner and 70 had different partners. A female was more likely to change partner if the first clutch had been laid relatively late than early in the season (Fig. 3; GLMER: $\mathrm{LR}_{1}=5.26, \mathrm{p}_{\text {boot }}=0.03$; laying date at first annual breeding attempt of females who were faithful or changed partner is respectively 24 March $\pm 2 \mathrm{~d}$ and 31 March \pm 2.4 ) and if brood size at the first nest was large rather than small (Fig. 4; $\mathrm{LR}_{1}=5.68, \mathrm{p}_{\text {boot }}=0.03$; brood size at first annual breeding attempt of females who were faithful or changed partner is $3.80 \pm 0.22$ and $4.54 \pm 0.21$ ). Age of the first male did not predict whether females divorced to produce a second annual breeding attempt $\left(\mathrm{LR}_{1}=0.0002, \mathrm{p}_{\text {boot }}=0.99\right)$.

At the first nest, females who stayed with the same partner to produce a second brood were more often paired with an adult than a yearling (50 out of 60 females were paired with an adult male, $83 \%$; for 6 females age of their partner was not known) while the male partner at the second annual brood of females who changed partner was a yearling in $50 \%$ of the cases (30 out of 60 females were paired with a yearling male; GLMER: $\mathrm{LR}_{1}=15.76, \mathrm{p}_{\text {boot }}=0.005$ ). In most cases the new mate of double-brooded females was producing his first annual brood in the study area (46 out of $60,77 \% ; \chi^{2}=17.06, \mathrm{p}<0.0001$ ), in 11 cases this was his 2 nd annual brood, in 2 cases a replacement clutch and in one case no information was available. Because few males changed partner to produce their second annual brood (18 out of 78,23\%), similar analyses were not possible.

The number of days separating the laying of the two annual clutches tended to be higher in faithful females who produced larger first broods compared to faithful females who had small broods $\left(\mathrm{LR}_{1}=3.13, \mathrm{p}_{\mathrm{boot}}=0.065\right)$, while there was no such a difference in females who divorced (average time interval between 1st and 2nd clutch of females who were faithful or divorced was $94.52 \pm 2.04$ and

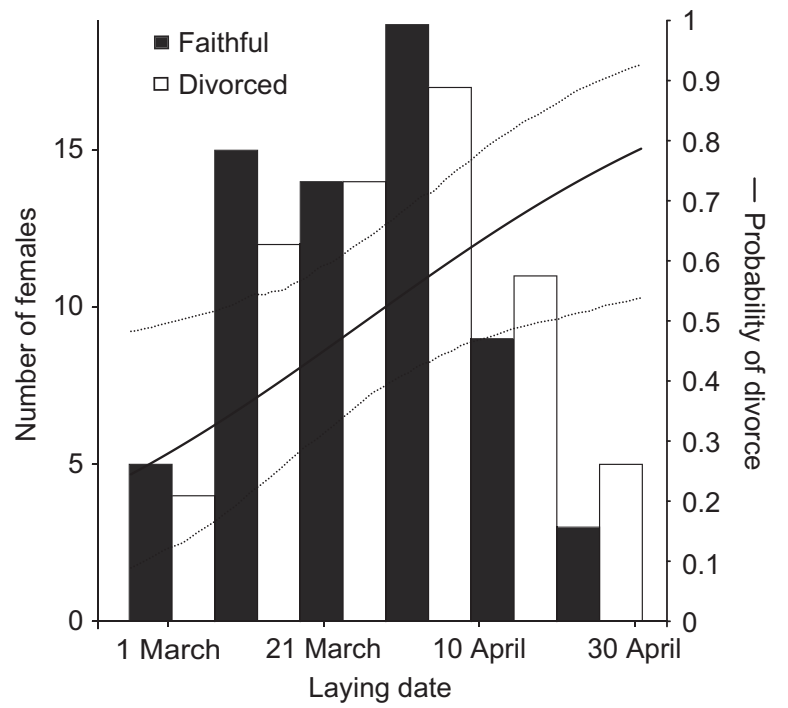

Figure 3. Distribution of laying dates of female barn owls who were faithful and those who were divorced between the first and second annual breeding attempts. The line represents the likelihood of changing partner to produce a second annual clutch in relation to laying date of first clutches. The dashed lines represent the 95\% confidence intervals. 


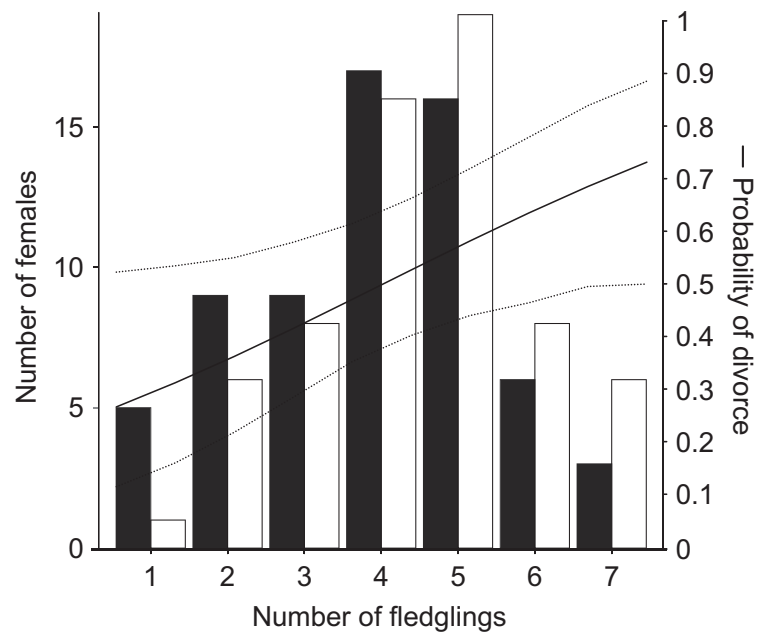

Figure 4. Distribution of the number of fledglings at first annual clutch of female barn owls who were faithful and those who divorced between the first and second annual breeding attempts. The line represents the likelihood of changing partner to produce a second annual clutch in relation to the number of fledglings at the first nest. The dashed lines represent the $95 \%$ confidence intervals.

$85.04 \pm 1.69 \mathrm{~d}$, respectively). In females who changed mate, the number of days between laying the first and second annual clutches was significantly lower when females bred late in the season rather than early in the season. In contrast, in faithful females the time interval between laying dates of the first and second annual clutches was not affected by laying date of their first clutch (Fig. 5; GLMER with log-transformed number of days between the two annual clutches, $\mathrm{n}=127$, interaction between 'laying date of 1 st clutch by divorce': $\mathrm{LR}_{1}=6.47$, $\mathrm{p}_{\text {boot }}=0.02$ ).

At the first nest, nestling body mass measured between 0 to $32 \mathrm{~d}$ of age (i.e. before their mother laid the second annual clutch) was not different whether their mother stayed with

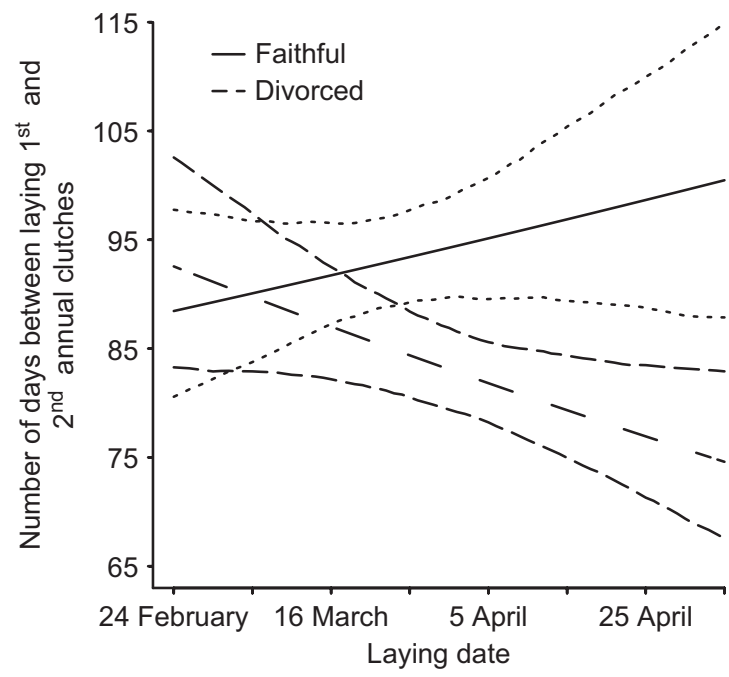

Figure 5. Number of days between first and second clutches in relation to laying date in females who were faithful and in females who divorced between the first and second annual breeding attempts. her partner or divorced to produce the second annual clutch (GLMER: $\mathrm{n}=66, \mathrm{LR}_{1}=1.2, \mathrm{p}_{\text {boot }}=0.35$ ).

\section{Potential fitness effects of double brooding}

The total number of offspring produced in the same year was higher in double-brooded than in single-brooded females (7.34 \pm 0.23 (range: $1-15$ fledglings) and 3.92 $\pm 0.12(0-9$ fledglings), respectively; (LMER: $\mathrm{n}=923, \mathrm{LR}_{1}=202.58$, $\mathrm{p}_{\text {boot }}=0.005$ ). Similar results apply to double-brooded males (6.79 \pm 0.25 fledglings) compared to single-brooded males (4.06 \pm 0.11 fledglings) (LMER: $\mathrm{n}=850, \mathrm{LR}_{1}=144.53$, $\left.\mathrm{p}_{\text {boot }}=0.005\right)$. In these analyses, we statistically controlled for laying date of the first annual clutch and age (yearling vs adult).

When considering only second annual clutches, clutch size decreased along the season (LMER with identity of female and year as random variables: $\mathrm{n}=103, \mathrm{LR}_{1}=12.31$, $\left.\mathrm{p}_{\mathrm{boot}}=0.005\right)$. The size of the second annual clutch was positively associated to the size of the first clutch $\left(\mathrm{LR}_{1}=18.2\right.$, $\left.\mathrm{p}_{\text {boot }}=0.005\right)$ but did not differ between adult and yearling females $\left(\mathrm{LR}_{1}=0.28, \mathrm{p}_{\text {boot }}=0.70\right)$ or between adult and yearling males $\left(\mathrm{LR}_{1}=0.70, \mathrm{p}_{\mathrm{boot}}=0.55\right)$. Furthermore, second annual clutches were larger than first annual clutches after controlling for laying date of the first clutch $\left(\mathrm{LR}_{1}=7.3, \mathrm{p}_{\text {boot }}=0.01,6.0 \pm 0.2\right.$ eggs (range: 4 to 12 eggs) and $5.43 \pm 0.24$ eggs (range: 2 to 12 eggs), respectively). Females who produced a second annual clutch produced a larger first clutch the following year compared to individuals who produced a single annual clutch the year before (LMER: $\mathrm{n}=377, \mathrm{LR}_{1}=8.11, \mathrm{p}_{\text {boot }}=0.01,6.28 \pm 0.19$ and $5.88 \pm 0.08$ eggs). Adult females compared to yearling females (GLMER: $\mathrm{n}=1050, \mathrm{LR}_{1}=5.75, \mathrm{p}_{\text {boot }}=0.02$ ) and females who produced two annual clutches compared to a single annual clutch $\left(\mathrm{LR}_{1}=9.29, \mathrm{p}_{\text {boot }}=0.004\right)$ had a higher probability of being recaptured as a breeder the following year. In males, adults were more often recaptured as breeders the following year than yearlings (GLMER: $n=955$, $\mathrm{LR}_{1}=12, \mathrm{p}_{\text {boot }}=0.002$ ), whereas the number of clutches produced in year $\mathrm{X}$ did not predict the probability of being recaptured in year $\mathrm{X}+1$ (GLMER: $\mathrm{n}=955, \mathrm{LR}_{1}=0.13$, $\left.\mathrm{p}_{\text {boot }}=0.72\right)$.

Breeding success at the second annual reproductive attempt was higher when the second clutch had been laid earlier in the season (GLMER: $\mathrm{n}=93, \chi^{2}{ }_{1}=10.21, \mathrm{p}=0.01$ ). In the same model, breeding success was not associated with female age $\left(\chi_{1}^{2}=0.36, \mathrm{p}=0.6\right)$ or male age $\left(\chi^{2}=2.32\right.$, $\mathrm{p}=0.23)$. Similarly, changing site between the first and second breeding attempts $\left(\chi_{1}^{2}=1.6, p=0.23\right)$, the time interval between laying the first and second annual clutches $\left(\chi^{2}=2.1, \mathrm{p}=0.21\right)$, the number of fledglings at the first clutch $\left(\chi_{1}^{2}=0.51, \mathrm{p}=0.54\right)$ or changing partner between first and second annual clutches $\left(\chi^{2}{ }_{1}=0.28, \mathrm{p}=0.72\right) \mathrm{did}$ not predict breeding success at the second reproductive attempt. However, at the first nest nestlings were lighter in body mass between 45 and $60 \mathrm{~d}$ of age if their father produced a second brood in the same year (Fig. 6; GLMER, 45-60 d: $\mathrm{n}=3106$ measurements of nestling body mass, $\left.\mathrm{LR}_{1}=5.71, \mathrm{p}_{\text {boot }}=0.02\right)$; in a similar model, nestling body mass was not related to whether their mother produced a second annual clutch $\left(\mathrm{n}=3139, \mathrm{LR}_{1}=0.05, \mathrm{p}_{\text {boot }}=0.8\right)$. 


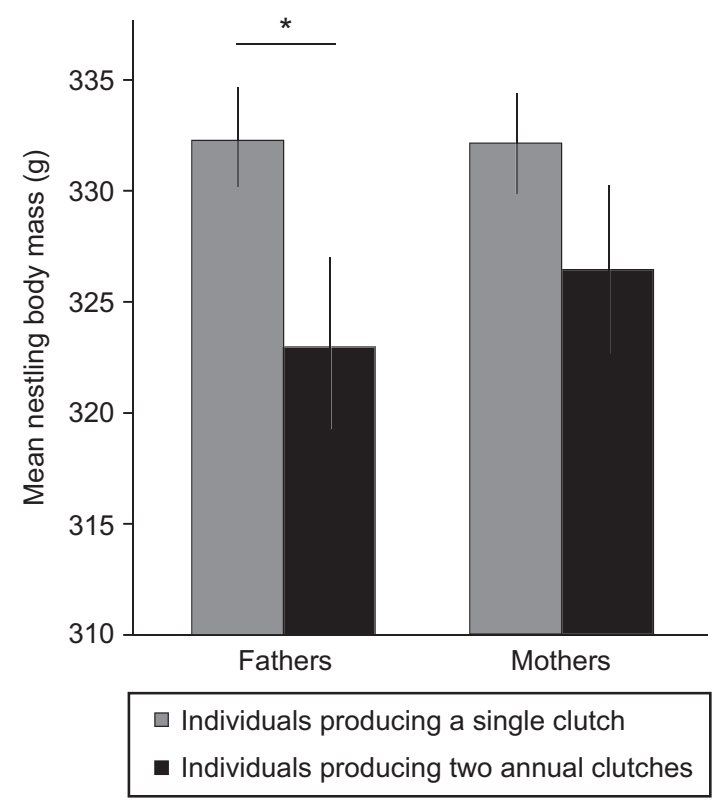

Figure 6. Mean body mass of nestling measured between 45-60 d old in relation to fathers and mothers who produce one or two annual clutches. The bars represent standard error.

Producing a second annual clutch did not predict the breeding success of females the following year (GLMER: $\left.\mathrm{n}=367, \chi^{2}{ }_{1}=0.22, \mathrm{p}=0.64\right)$ nor did female age $\left(\chi^{2}{ }_{1}=0.38\right.$, $\mathrm{p}=0.52)$ or laying date $\left(\chi^{2}=0.2, \mathrm{p}=0.65\right)$. In a similar model for males, these factors were not related to the breeding success the following year (number of annual clutches: $\chi^{2}{ }_{1}=2.04, \mathrm{p}=0.16$; male age: $\chi^{2}{ }_{1}=1.8, \mathrm{p}=0.21$ ).

\section{Discussion}

\section{Determinants of double brooding}

Double brooding was common in our population of Barn owls and varied between years and sexes with on average $13 \%$ of the females and $8 \%$ of the males producing a second brood (Table 1). The likelihood of producing a second annual clutch was higher if the first clutch had been laid early rather than late in the season (Fig. 1) and if males had few offspring at their first annual clutch. The effect of an early initiation of reproductive activities on the probability of producing a second annual brood is in line with previous studies in various species (Beissinger 1986, Geupel and Desante 1990, Ogden and Stutchbury 1996, Monroe et al. 2008, Townsend et al. 2013, Carro et al. 2014, Hoffmann et al. 2015) including the barn owl (Baudvin 1986, Marti 1994).

Variation in the propensity to breed twice in the same year could be explained by individual-specific life history strategies, with individuals differentially trading selfmaintenance against the number of reproduction events (Saino et al. 1999). An alternative hypothesis is that the production of a second annual brood is related to body condition (Jacobs et al. 2013, Hoffmann et al. 2015), hunting ability or territory quality (Nagy and Holmes 2005a). Mainly individuals in prime condition may produce a second annual brood or those breeding in high quality territories, and they may show a high survival prospect because they are in good condition rather than because they produce a second annual brood. Because this result was verified for females but not for males, we propose that individual quality (in females) rather than territory quality explains why double-brooders have a higher survival prospect.

The fact that in females brood size did not predict double brooding but divorce suggests that the male presence is mandatory to complete parental duties up to offspring independence. If brood size is large, the father has to invest substantial effort to feed his offspring giving him little time to invest in the preparation of a second nest (e.g. copulation, courtship feeding). This may induce the female to search for another male who is free of parental care duties as shown by our data: $77 \%$ of the new partners of deserting females were not observed breeding in the study area the same year and $3 \%$ of them had failed their first annual clutch. Deserting females will therefore save time by quickly producing their second brood instead of waiting for their first male to become free from paternal duties to initiate a second breeding attempt with him. This is supported by the fact that deserting females double-brooded earlier than faithful females. Alternatively, because double brooding males produced poorer quality offspring at the first nest, females may desert their first brood to prevent males from double brooding and impairing the quality of their offspring.

As the success of second broods decreases along the season, females should desert early in the season but only if their first mate can assume parental care duties alone. However, this may not be the only reason as females having an early first clutch deserted their offspring at an older age than late breeders. If deserting young offspring may accelerate the production of a second brood, this behaviour may negatively affect the last-born offspring who still require the presence of their mother. Therefore, deserting young offspring may be an option only late in the season because fledging success at the second annual breeding attempt decreases along the season. Another non-mutually exclusive explanation is that rearing the first brood may be more costly early than late in the season and for this reason females may desert their offspring at an older age early in the season in order to assist their mate for longer. The fact that females who divorced re-nested farther from their first brood compared to faithful females who stayed in the proximity of their first brood suggests that they were no longer contributing to parental care at the first nest.

\section{Cost and benefits of double brooding}

Similarly to the Tengmalm's owl (Korpimaki et al. 2011), double-brooded females produced on average more fledglings (7.34) per year than individuals producing a single annual brood (3.92 fledglings). Because brood size at the first nest did not predict double brooding in females, we conclude that in females the adaptive function of double brooding is not to compensate a low reproductive success at the first annual breeding attempt but rather to increase the overall reproductive success, if environmental conditions are sufficiently good to allow the production of a second annual brood. Double-brooded males produced also more offspring (6.79) than single brooded males (4.06). However, the fact 
that males with fewer offspring at their first brood had a higher propensity to produce a second brood could also suggest that males compensate a low reproductive success at the first breeding attempt with a second annual brood, implying that they have still enough energy to breed again. Alternatively, producing a second annual brood may impair the survival of fledglings at the first annual clutch (Eldegard and Sonerud 2009). As mentioned above, however, another explanation is that males, for whom the first brood is large, do not have the time to start a second breeding attempt. Accordingly, the negative impact of brood size on double brooding has already been reported in other bird species (Verboven and Verhulst 1996, Nagy and Holmes 2005a, Parejo and Danchin 2006, Eldegard and Sonerud 2009).

At the first nest, nestling body condition decreased if their father, but not mother, produced a second annual clutch. This further emphasises the claim that the female presence is often not mandatory to complete parental care duties in contrast to the male presence (Eldegard and Sonerud 2012). Thus, the cost of paternal double brooding is in part paid by the offspring, as shown in the snow bunting Plectrophenax nivalis (Smith and Marquiss 1995), whereas the cost of maternal double brooding may be paid by the male who has to pursue rearing activities alone. Nevertheless, double brooding did not appear to translate into a reduction in adult survival, since double brooding in a given year did not impair reproductive success or the probability of reproducing the following year, which contrasts with a study in the spotted owl Strix occidentalis occidentalis (Stoelting et al. 2015). We are aware that in correlative studies such as in our case, it might be difficult to identify the costs of double brooding paid by the parents as shown experimentally in the great tit Parus major (Verhulst 1998). Accordingly, in the barn owl we found that double-brooded females produced larger clutches the following year than single-brooded females and they were more often recaptured. This may indicate that high quality individuals are more likely to produce two broods than poor quality conspecifics.

\section{Conclusion}

Double brooding is an adaptive strategy as double-brooded barn owls produced in total more fledglings than singlebrooded conspecifics. Although the timing of laying the first clutch predicted double brooding in both males and females, each sex adopts different reproductive strategies. Females should pair with high quality males to produce large first broods and ensure that their partner feeds the progeny at a high rate. Even if producing many offspring at the first nest may force males to invest in parental care rather than in the production of a second annual brood, females have still the possibility to desert their first nest to pair with a new partner. Because the success of second broods decreases throughout the season, females should desert early in the season but only if their first mate can assume parental care duties alone. If the female strategy to produce two annual broods is clearly advantageous, in males the situation is more complex. Males who raise a small number of offspring at the first breeding attempt are more likely to produce a second annual brood and have in total more offspring than single-brooded males. However, because double-brooded males produce lower quality of offspring at the first nest raises the question of whether males should better produce two annual brood or a single large brood.

With its ability to produce several large clutches in a single breeding season, the barn owl adopts a reproductive strategy similar to passerines rather than the conventional reproductive strategy observed in most raptors and owls (Newton 1979). In temperature regions, it may allow the barn owl to compensate for frequent population crashes due to pronounced variation in food supply and harsh winters (Henny 1969, Marti and Wagner 1985, Muller 1991, Altwegg et al. 2006). Double brooding in the barn owl is also common at low latitudes (Muller 1991) where environmental conditions are more stable, and hence where fluctuations in population sizes may be less pronounced than in temperate regions. The factors that determine the propensity to produce multiple broods in a single season may therefore differ between populations emphasizing the need of studying the reproductive biology of this bird at different latitudes. A comparative study across bird species may also be useful to determine the relative importance of ecological, behavioural and life history traits in the determinism of double brooding.

Acknowledgements - This research was financially supported by the Swiss National Science Foundation for funding (31003A120517). We are grateful to all the farmers who allowed us to install nest-boxes in their barns and to our colleagues who contributed to the collection of the data during all these years. We are also thankful to Jan-Åke Nilsson and Geir A. Sonerud for their comments and propositions that helped us improve the content of this paper.

\section{References}

Alker, P. J. and Redfern, C. P. F. 1996. Double brooding and polygyny in sedge warblers Acrocephalus schoenobaenus breeding in north-west England. - Bird Study 43: 356-363.

Altwegg, R., Roulin, A., Kestenholz, M. and Jenni, L. 2006. Demographic effects of extreme winter weather in the barn owl. - Oecologia, 149: 44-51.

Andrusiak, L. A. 1994. Nestling and roosting habitat and breeding biology of the barn owl (Tyto alba) in the lower mainland of British Columbia. - MSc thesis, Univ. of B.C., Vancouver, BC.

Baudvin, H. 1986. La reproduction de la chouette effraie (Tyto $a l b a)$. - Le Jean le Blanc 25: 1-125.

Beissinger, S. R. 1986. Demography, environmental uncertainty, and the evolution of mate desertion in the snail kite. - Ecology 67: 1445-1459.

Béziers, P. and Roulin, A. 2015. Data from: Double brooding and offspring desertion in the barn owl Tyto alba. - Dryad Digital Repository, < http://dx.doi.org/10.5061/dryad.9sk18>.

Bunn, D. S., Warburton, D. S. and Wilson, R. D. S. 1982. The barn owl. - Buteo Books.

Carro, M. E., Mermoz, M. E. and Fernandez, G. J. 2014. Factors affecting the probability of double brooding by southern house wrens. - J. Field Ornithol. 85: 227-236.

Courtney, J. and Debus, S. J. S. 2006. Observations on the post-fledging period of the barn owl Tyto alba. - Aust. Field Ornithol. 23: 109-124.

Curtis, O., Malan, G., Jenkins, A. and Myburgh, N. 2005. Multiple-brooding in birds of prey: South African black sparrowhawks Accipiter melanoleucus extend the boundaries. - Ibis 147: 11-16. 
Debrot, A. O., De Freitas, J. A., Brouwer, A. and Kooy, M. V. 2001. The Curacao barn owl: status and diet, 1987-1989. - Caribb. J. Sci. 37: 185-193.

Debus, S. J. S. 1994. The sooty owl Tyto tenebricosa in New South Wales. - Aust. Birds 28: 4-19.

Debus, S. J. S. 1997. Aspects of the biology of captive-bred, hackreleased masked owls Tyto novaehollandie. - Aust. Raptor Stud. II: $14-33$.

Eldegard, K. and Sonerud, G. A. 2009. Female offspring desertion and male-only care increase with natural and experimental increase in food abundance. - Proc. R. Soc. B 276: 1713-1721.

Eldegard, K. and Sonerud, G. A. 2012. Sex roles during postfledging care in birds: female Tengmalm's owls contribute little to food provisioning. - J. Ornithol. 153: 385-398.

Faraway, J. J. 2006. Extending the linear model with R. - Chapman and Hall, CRC.

Fargallo, J. A., Blanco, G. and Sotolargo, E. 1996. Possible second clutches in a Mediterranean montane population of the Eurasian kestrel (Falco tinnunculus). - J. Raptor Res. 30: 70-73.

Geupel, G. R. and Desante, D. F. 1990. Incidence and determinants of double brooding in wrentits. - Condor 92: 67-75.

Henny, C. J. 1969. Geographical varaition in mortality rates and production requirements of barn owl (Tyto alba ssp). - BirdBanding 40: 277-290.

Hoffmann, J., Postma, E. and Schaub, M. 2015. Factors influencing double brooding in Eurasian hoopoes Upupa epops. - Ibis 157: 17-30.

Husby, A., Kruuk, L. E. B. and Visser, M. E. 2009. Decline in the frequency and benefits of multiple brooding in great tits as a consequence of a changing environment. - Proc. R. Soc. B 276: 1845-1854.

Jacobs, A. C., Reader, L. L. and Fair, J. M. 2013. What determines the rates of double brooding in the western bluebird? Condor 115: 386-393.

Jamieson, S. E. 2011. Pacific dunlin Calidris alpina pacifica show a high propensity for second clutch production. - J. Ornithol. 152: 1013-1021.

Kniprath, E. and Stier, S. 2008. Schleireule Tyto alba: mehrfachbruten in Südniedersachsen. - Eulen-Rundblick 58: 41-45.

Korpimaki, E., Salo, P. and Valkama, J. 2011. Sequential polyandry by brood desertion increases female fitness in a bird with obligatory bi-parental care. - Behav. Ecol. Sociobiol. 65: 1093-1102.

Kuitunen, M., Jantti, A., Suhonen, J. and Aho, T. 1996. Food availability and the male's role in parental care in doublebrooded treecreepers Certhia familiaris. - Ibis 138: 638-643.

Lander, E., Lopez, J., Diaz, C. and Colmenares, M. 1991. Population biology of the barn owl (Tyto alba) in Guarico State, Venezuela. - Birds Prey Bull. 4: 167-173.

Lenton, G. M. 1984a. The feeding and breeding ecology of barn owls Tyto alba in Peninsular Malaysia. - Ibis 126: 551-575.

Lenton, G. M. 1984b. Malayan barn owl project. - Br. Ecol. Soc. Bull. 15: 78-79.

Malan, G., Crowe, T. M., Biggs, R. and Herholdt, J. J. 1997. The social system of the pale chanting goshawk Melierax canorus; monogamy v polyandry and delayed dispersal. - Ibis 139: 313-321.

Marks, J. S. and Perkins, A. E. H. 1999. Double brooding in the long-eared owl. - Wilson Bull. 111: 273-276.

Marti, C. D. 1994. Barn owl reproduction - patterns and variation near the limit of the species distribution. - Condor 96: 468-484.

Marti, C. D. 1997. Lifetime reproductive success in barn owls near the limit of the species' range. - Auk 114: 581-592.

Marti, C. D. and Wagner, P. W. 1985. Winter mortality in common barn owls and its effect on population-density and reproduction. - Condor 87: 111-115.

Martinez, J. A. and Lopez, G. 1999. Breeding ecology of the barn owl (Tyto alba) in Valencia (SE Spain). - J. Ornithol. 140: 93-99.
Millsap, B. A. 1990. Double brooding by Forida burrowing owls. - Wilson Bull. 102: 313-317.

Monroe, A. P., Hallinger, K. K., Brasso, R. L. and Cristol, D. A. 2008. Occurrence and implications of double brooding in a southern population of tree swallows. - Condor 110: 382-386.

Moore, D. J. and Morris, R. D. 2005. The production of second clutches in the common tern: proximate effects of timing and food supply. - Waterbirds 28: 458-467.

Morrison, J. L. 1998. Effects of double brooding on productivity of crested caracaras. - Auk 115: 979-987.

Muller, Y. 1991. Les secondes nichées chez la chouette effraie (Tyto alba). Rapace nocturne. - Actes due 30 Colloque interrégional d'ornithologie Porrentruy, Suisse, pp. 173-188.

Nagy, L. R. and Holmes, R. T. 2005a. Food limits annual fecundity of a migratory songbird: an experimental study. - Ecology 86: 675-681.

Nagy, L. R. and Holmes, R. T. 2005b. To double-brood or not? Individual variation in the reproductive effort in blackthroated blue warblers (Dendroica caerulescens). - Auk 122: 902-914.

Newton, I. 1979. Population ecology of raptors. - T. and A. D. Poyser.

Ogden, L. J. E. and Stutchbury, B. J. M. 1996. Constraints on double brooding in a neotropical migrant, the hooded warbler. - Condor 98: 736-744.

Parejo, D. and Danchin, E. 2006. Brood size manipulation affects frequency of second clutches in the blue tit. - Behav. Ecol. Sociobiol. 60: 184-194.

Roulin, A. 2002. Offspring desertion by double-brooded female barn owls (Tyto alba). - Auk 119: 515-519.

Roulin, A. 2004. The function of food stores in bird nests: observations and experiments in the barn owl Tyto alba. - Ardea 92: 69-78.

Roulin, A., Ducrest, A. L. and Dijkstra, C. 1999. Effect of brood size manipulations on parents and offspring in the barn owl Tyto alba. - Ardea 87: 91-100.

Saino, N., Calza, S., Ninni, P. and Moller, A. P. 1999. Barn swallows trade survival against offspring condition and immunocompetence. - J. Anim. Ecol. 68: 999-1009.

Shawyer, C. 2003. Observations during 2003 season. - BTO Newsletter 2.

Smith, R. D. and Marquiss, M. 1995. Production and costs of nesting attempts in snow buntings Plectrophenax nivalis: why do they attempt second broods? - Ibis 137: 469-476.

Stahlecker, D. W. and Griese, H. J. 1977. Evidence of double brooding by American kestrels in Colorado high plains. - Wilson Bull. 89: 618-619.

Steenhof, K. and Peterson, B. E. 1997. Double brooding by American kestrels in Idaho. - J. Raptor Res. 31: 274-276.

Stoelting, R. E., Gutierrez, R. J., Kendall, W. L. and Peery, M. Z. 2015. Life-history tradeoffs and reproductive cycles in spotted owls. - Auk 132: 46-64.

Stopper, H. 1983. Beobachtungen bei der Futterung von Schleiereulen (Tyto alba) an traditionellen Uberwinterungsplatzen. - Ornithol. Mitteilungen 35: 88-89.

Szekely, T., Cuthill, I. C. and Kis, J. 1999. Brood desertion in Kentish plover: sex differences in remating opportunities. - Behav. Ecol. 10: 185-190.

Tarwater, C. E. and Beissinger, S. R. 2013. Opposing selection and environmental variation modify optimal timing of breeding. - Proc. Natl Acad. Sci. USA 110: 15365-15370.

Taylor, I. R. 1993. Age and sex determination of barn owls Tyto alba alba. - Ringing Migration 14: 94-102.

Toland, B. R. 1985. Double brooding by American kestrels in central Missouri. - Condor 87: 434-436.

Townsend, A. K., Sillett, T. S., Lany, N. K., Kaiser, S. A., Rodenhouse, N. L., Webster, M. S. and Holmes, R. T. 2013. 
Warm springs, early lay dates, and double brooding in a North American migratory songbird, the black-throated blue warbler. - PLoS One 8: e59467.

van Heerden, P., Ellmann, A. and Van Zyl, B. 1994. Multiple breeding by rock kestrels in the Tygerberg residential area. Birding S. Afr. 46: 121-122.

Verboven, N. and Verhulst, S. 1996. Seasonal variation in the incidence of double broods: the date hypothesis fits better than the quality hypothesis. - J. Anim. Ecol. 65: 264-273.
Verhulst, S. 1998. Multiple breeding in the great tit, II. The costs of rearing a second clutch. - Funct. Ecol. 12: $132-140$.

Verhulst, S. and Hut, R. A. 1996. Post-fledging care, multiple breeding and the costs of reproduction in the great tit. - Anim. Behav. 51: 957-966.

Verhulst, S., Tinbergen, J. M. and Daan, S. 1997. Multiple breeding in the great tit. A trade-off between successive reproductive attempts? - Funct. Ecol. 11: 714-722. 